\title{
ARTICLE
}

\section{Listening to the Quiet Voices: Unlocking the Heart of Engineering Grand Challenges}

\author{
George Catalano*
}

* Department of Bioengineering, Binghamton University, catalano@binghamton.edu

According to the National Academy of Engineering, the list for the Grand Challenges for Engineering are: (1) Make solar energy economical; (2) Provide energy from fusion; (3) Develop carbon sequestration methods; (4) Manage the nitrogen cycle; (5) Provide access to clean water; (6) Restore and improve urban infrastructure; (7) Advance health informatics; (8) Engineer better medicines; (9) Reverseengineer the brain; (10) Prevent nuclear terror; (11) Secure cyberspace; (12) Enhance virtual reality; (13) Advance personalized learning; and (14) Engineer the tools of scientific discovery. Surely, it may be difficult to find many who would find any reason to disagree with the identification of any of these topics for both the present and future engineers. Rather than object to what is included, I would like to raise the issue of what has been neglected in this list and far too often in engineering-listening to the quiet voices that speak from within each of us from our heart. I am suggesting the act of listening as one additional entry for this most important list.

In my view, one set of skills that our profession does not encourage very well is stopping and listeningstopping and listening to each other, stopping and listening to life around us, or stopping and listening even to ourselves. This is a skill that, given the pace of our modern society, technological advances and our cultural conditioning, must be cultivated for it likely will simply either never develop or quickly wither away. The question at hand then becomes how does one cultivate the ability to stop and to listen? The present work offers one such path though clearly there are countless others.

KEYWORDS: contemplative pedagogy, Grand Challenges, listening, mindfulness

\section{INTRODUCTION}

The National Academy of Engineering published its Grand Challenges for Engineering in 2008. The challenges ranged from making solar energy economical to providing access to clean water to reengineering the brain, to list just a few. Surely, it may be difficult to find many who would find reason to disagree with the identification of any of these topics for both present and future engineers. I would like to raise the issue of what has been neglected in the Grand Challenges for Engineering and far too often in engineering generally-listening to the quiet voices that speak from within each of us, from our heart. I am suggesting the act of listening as one additional entry for the Grand Challenges.

In my view, our profession does not encourage stopping and listening to each other, to life around us or even to ourselves. An obvious question in response is to ask, "why is listening so important?" I will argue in this essay that listening is an important aspect of learning and it is a skill which we neglect at our own peril! Listening, given the pace of our modern society, technological advances and our cultural conditioning, must be cultivated, for it surely will either develop and become 
stronger or quickly wither away, and eventually disappear. The question at hand then becomes, "how might we cultivate the ability to stop and to listen?" The present work offers a description of one such path, though clearly there are countless others. The path chosen is one based upon an adaptation of a contemplative pedagogy.

In a 1993 talk at Berea College, Parker Palmer pointed out that "every way of knowing becomes a way of living, every epistemology becomes an ethic." He argued that the current epistemology has spawned an associated ethic of violence. Surely, science (and engineering) has brought enormous advances, but we cannot turn away from the central fact that the modern emphasis on objectification predisposes us to an instrumental and manipulative way of being in the world. As Palmer suggested, knowing does, indeed, grow into a way of living. The implications of this position are important in light of our work as engineers. It is not calling for a rollback of science and engineering, but rather a resituating of them within a greater vision of what knowing and living are really all about. That re-imagination of knowing could have deep consequences for education, consequences that give a prominent place to contemplative pedagogies.

Ultimately the question becomes, "what is the necessary business of education in general and engineering education specifically?" Postman and Weingartner offer the following set of questions and ideas:

[Is it] to create eager consumers? To transmit the dead ideas, values, metaphors and information of three minutes ago? To create smoothly functioning bureaucrats? These aims are truly subversive as they undermine our chances of survival ... we would like to see the schools go into the anti-entropy business. Now that is subversive, too. But the purpose is to subvert attitudes and beliefs and assumptions that foster chaos and uselessness. (1969, p. 15)

Perhaps stopping and listening may offer engineering a way out of the instrumental and manipulative way of being in the world. I am reminded of the words of Chief Dan George:

One thing to remember is to talk to the animals. If you do, they will talk back to you. But if you don't talk to the animals, they won't talk back to you, then you won't understand, and when you don't understand you will fear and when you fear you will destroy the animals, and if you destroy the animals, you will destroy yourself. (Levey \& Levey, 1998, p. 266)

These kinds of exchanges take time and reflection and point to a need for our profession to slow down and to listen much more deliberately than we have in the past, or we run the risk of destroying our very planet.

\section{Contemplative Pedagogy and Learning to Listen}

One approach to developing the ability to slow down and to listen can be found in what is referred to as contemplative pedagogy. One of the most powerful transformative interventions developed by humanity is contemplative practice or meditation (Hart, 2004). It has been specifically designed to move human cognition from a view of reality of separateness and dualism to one in which the interconnectedness of reality is directly perceived. Contemplative practice works on the human psyche to shape attention into a far suppler instrument, one that can appreciate a wide range of worldviews and even sustain the paradoxes of life, ultimately drawing life's complexity into a gentle, non-judgmental awareness. 
Educators at hundreds of North American universities and colleges are increasingly appreciating the usefulness of secular contemplative practice (Zajonc, 2006). At conferences and summer schools at Columbia University, Amherst College and elsewhere, for example, professors have gathered to share their experiences in the emerging area of contemplative pedagogy. Their efforts range from simple silence at the start of class to exercises that school attention; and most recently, to innovative contemplative practices that relate directly to course content.

Jon Kabat-Zinn (2005) has spoken about the unification of knowing through contemplation, reminding us both how available mindfulness is, but also how difficult it can be to bring full awareness to the entirety of life. According to Zajonc (2005), the curricula offered by our institutions of higher education have largely neglected this central, if profoundly difficult task of learning to love, which is also the task of learning to live in true peace and harmony with others and with nature, which I believe is our ultimate responsibility in engineering. He adds,

\begin{abstract}
We are well-practiced at educating the mind for critical reasoning, critical writing, and critical speaking, as well as for scientific and quantitative analysis. But is this sufficient? In a world beset with conflicts, internal as well as external, isn't it of equal if not greater importance to balance the sharpening of our intellects with the systematic cultivation of our hearts? Do not the issues of social justice, the environment, and peace education all demand greater attention and a more central place in our universities and colleges? (Zajonc, 2005)
\end{abstract}

Marilyn Nelson (2005) has relayed the story of teaching silence to those whose lives take them into war and conflict. Nelson added that contemplative pedagogy does not involve teaching a technique. Rather, it is teaching an "attitude [of openness to explore] the several ways in which listening can occur and how one can listen for and to silence."

Contemplative practices quiet the mind in order to cultivate a personal capacity for deep concentration and insight. Examples of contemplative practice include not only sitting in silence but also many forms of single-minded concentration including meditation, contemplative prayer, mindful walking, focused experiences in nature, yoga and other contemporary physical or artistic practices. The concept of contemplative practice is as old as the world's religions. Every major religious tradition includes forms of contemplative practice, such as prayer, meditation, and silent time in nature. Many practices remain rooted in their religions, and others have grown in secular settings.

\title{
A Complementary PARAdigm Of StUdy: CONTEMPLATIVE INQUIRY
}

One example of a contemplative practice is contemplative inquiry. Zajonc suggests the practice of contemplative inquiry as an essential modality of study complementary to the dominant analytic methods now practiced in every field (Palmer \& Zajonc, 2010). Zajonc further argues that "such inquiry is at the true heart of higher education" and is an expression of the "epistemology of love" wherein epistemology refers to a theory of knowledge or, in other words, how we know what we know. To describe the method of contemplative inquiry, Zajonc delineates seven stages in this epistemology (see Figure 1).

In the first stage, respect, we may ask if in fact we respect the integrity of the subject of our study. Do we respect the other, be it a river, the Earth's atmosphere or oceans, our employers, our clients, the societies and cultures which our technological advances impact? Rilke (2002) suggested that when we truly respect the other, we "border and protect them" as we seek to know and understand them better. I wonder in engineering how often we introduce this concept of respect into our classrooms. Perhaps in engineering design we might, but rarely in other engineering courses. 
Gentleness, or according to Goethe (1994), "gentle empiricism," lies in stark contrast to the scientific method of the Age of Science or Enlightenment. Rather than Bacon's instruction of "putting nature on the rack," gentleness suggests approaching the object of our attention without distortion. I would argue that seeing without distortion offers a much greater insight into what lies before us. Intimacy, the third stage, calls upon us to forgo the notion of disengaged science for the sake of objectivity but rather to approach the object of our attention with delicateness and respect. As quantum mechanics suggests, the notion of separateness of subject and object is misleading at best. According to Palmer and Zajonc, "We can still retain clarity and balanced judgment close-up if we remember to exercise restraint and gentleness" (2010, p. 95). Vulnerability challenges us to put aside a dominating arrogance and to learn to be comfortable with not knowing, with uncertainty and with ambiguity. Being able to deal with uncertainty and ambiguity is at the very heart of what, for example, accrediting organizations in engineering are requiring for tomorrow's engineers. Participation asks us to join with the other while maintaining full awareness and clarity of mind, or in Emerson's words, "the intellect being where and what it sees" (2000, p. 298). Transformation requires that we are transformed by the experience, that is, what was outside is now inside. We are shaped or developed or sculpted by the experience. Imaginative insight can be once again described most eloquently by Goethe (1994) who likened imaginative insight to the formation of a new organ: "Every object well-contemplated opens a new organ of perception in us."

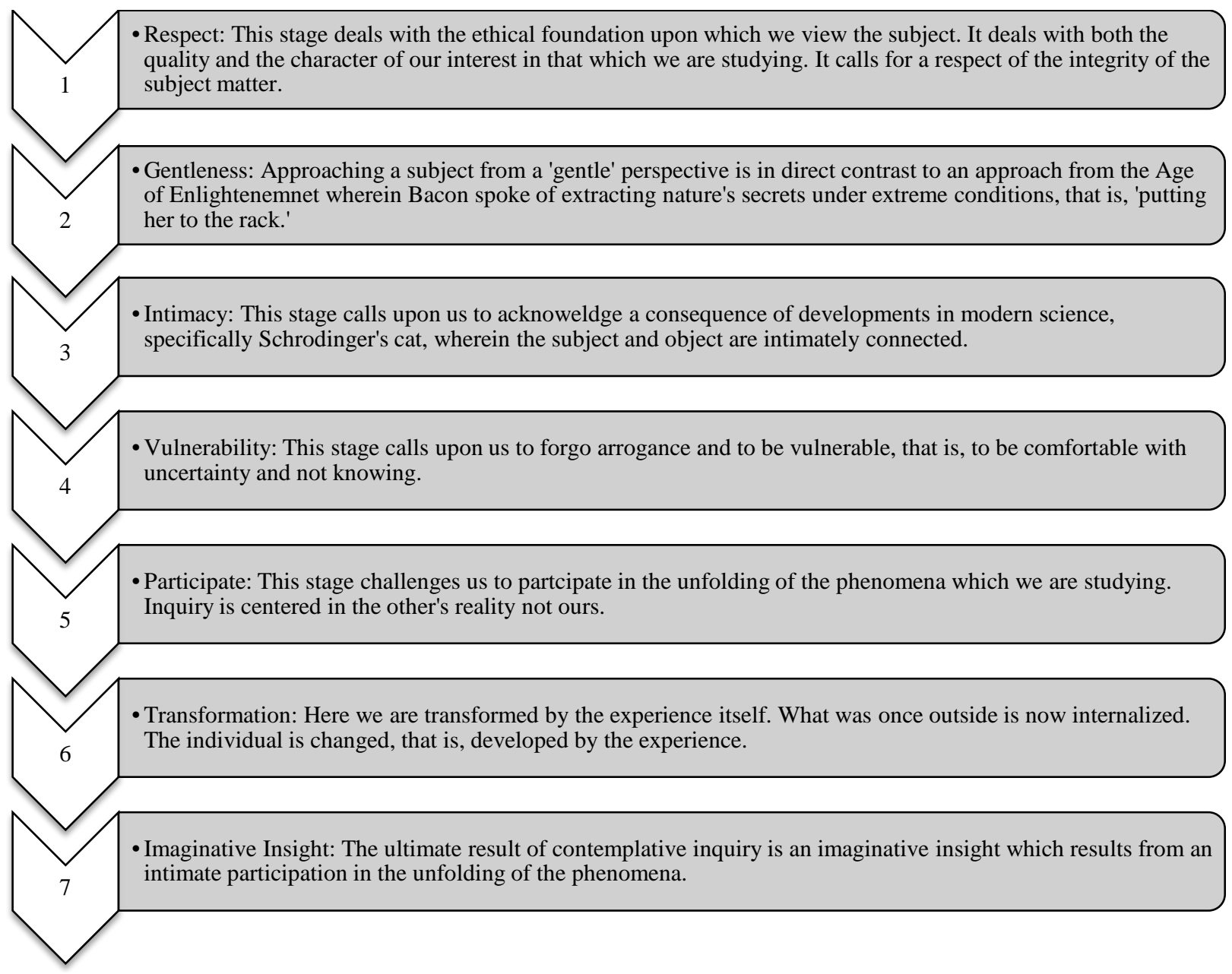

Figure 1. Seven stages of contemplative inquiry. 


\section{Application to Engineering Science CourSe: FLUID MeChANICS OF LIVING SYSTEMS}

As an illustrative example, the method of contemplative inquiry is developed for an undergraduate engineering course in fluid mechanics in our bioengineering program. From the outset, students may be told that the fluids course is going to be taught using a different paradigm than perhaps they had experienced previously in engineering. The ultimate goal for the course is given to them as the development of that imaginative insight, that quality of understanding that describes the "creative insight which every scientist, scholar, and artist recognizes as the axis around which their work turns but which cannot be produced on demand" (Palmer \& Zajonc, 2010, p. 96). This insight then is the ultimate reasoning for listening. That is all that may be offered about this mysterious goal though it can again be brought back to their attention throughout the semester.

The writing strategies Nelson (2005) utilized in the course she taught at the United States Military Academy at West Point included: "journaling, which focuses and complements the meditation experience; free-writing, which comes close to recording 'inner speech'; and clustering, which taps into the creative, intuitive, right-brain function that lies at the core of meditation." Each of these strategies are adapted for the bioengineering fluids course. A regular class session includes five minutes of meditation at the beginning of each class meeting; fifteen minutes of daily meditation outside of class; journaling; and various writing exercises. Each class period begins and ends with a moment of quiet contemplation. Various techniques included my simply standing quietly in front of the classroom to the recitation of a mantra to a ringing of a bell and a calling for undivided attention to some object at the front of the room. I muse about how much easier my teachers had it in my high school-a Roman Catholic college preparatory school taught by strict Christian Brothers in long, flowing and intimidating black robes! There, each class hour started with an invocation to the divine mystery and a remembrance of the patron saint of that particular order.

My intention is to begin with a meditative practice borrowing from the practice of yoga. The immediate response is likely to be a combination of shock, disbelief and laughter but gradually as each day passes, my hope and suspicion is that the immediate reaction will be slowly replaced by many more thoughtful looks and much less time passing before quiet and order are present.

Insight, also referred to as Vipassana meditation, is a simple form of Buddhist meditation that calms and concentrates the mind (Rosenberg, 2004). The practice originated with the Buddha over 2,500 years ago. In the form offered here, the practice starts with learning to keep one's attention on the breath. This is a form of concentration practice. The course progresses through mindfulness practices, such as noticing the body, the feelings, one's thoughts and one's life patterns. As the practice continues, one learns to be more present in the moment.

This practice is a meditation practice and not a religious system of belief. As an introduction for students to the practice of meditation, five different techniques are presented, as outlined by Fleischman (1999):

- Mindfulness of breathing

- Mindfulness of the body

- Mindfulness of feelings

- Mindfulness of the mind

- Mindfulness of patterns 
These different techniques are to be presented during the first five weeks of the class. Subsequently, students will be asked to mediate upon the following subject matter, each of some considerable relevance to the course.

As the course is focused upon the flow of fluids, it is easy to make connections among the flows in pipes as observed by Reynolds in 1895, the flow of oxygen in our respiratory systems including our lungs as well as the lungs of other living animals, and the flow of blood in our arteries and our veins as well as those same flows in other living creatures (Vogel, 1997). Further, similar analytical ideas will be extended to the flow of sap in trees. Students will be asked then to meditate on the flow of air in their respiratory systems, the flow of blood in their cardiovascular systems and the slow movement of sap in the majestic sugar maple trees that inhabit the northeast region of the United States.

After some preliminary development in class, we shall focus upon the lift and drag characteristics of single birds and migratory flocks of birds discussing similarities and differences between the low speed aerodynamics of our technological world to that of the natural world (Alexander, 2004; Vogel, 1997). Students will be asked then to meditate on the migrations that occur throughout the year as native birds deal with the changing weather patterns we experience throughout the year.

Comparisons between laminar fluid mechanics and turbulent fluid mechanics will be made. The closure problem and its implications in engineering will be considered. Focus will be placed on the uncertainty that surrounds turbulent flow fields such as those encountered in the flow of blood in the human heart. Somewhat unexpectedly, the lack of turbulence in the heart indicates a weakened heart in a seriously weakened condition. Students will be asked then to meditate on the flow of blood in their bodies both through the pumping action of the heart and the cleansing action of the kidneys.

Emphasis will be placed upon how accounting and conservation equations are used to derive familiar laws, such as Kirchhoff's current and voltage laws, Newton's laws of motions, Bernoulli's equation and others (Berger, 1996). Extensive examples that span the breadth of modern bioengineering, including physiology, biochemistry, tissue engineering, biotechnology and instrumentation shall each be a focus of a weekly meditation. As an example, the birth rate, death rate and the movement of a species into and out of a sanctuary such as the wolves at Isle Royale can be considered (Peterson, 1995).

\section{Proposed Research OUtLINe}

The research question for this particular effort is the following: "Do students develop a deeper understanding of the course material when presented concepts in an environment incorporating a contemplative pedagogy?"

In response to the proposed integration of meditation and other contemplative activities into the course, a socio-cultural theory offered by Cole and Engstrom (1993) shall be used as the theoretical framework for the study. Vygotsky (1978) conceived socio-cultural theory in the early 1920's. It emphasizes the central role of social relationships and culturally constructed artifacts in organizing thinking. It attempts to theorize and provide methodological tools for investigating higher cognitive processes by which social, cultural and historical factors shape human functioning. Cole and Engstrom's model provides several dimensions along which one can study the classroom as an activity system. They identify factors, other than the subject matter or students or teachers, which 
must be taken into account when trying to understand how knowledge is distributed within a system. These factors include the curriculum, language use, rules and community.

A mixed methods approach will be taken in assessing the results (Johnson \& Onwuegbuzie, 2004). This approach involves the collection and/or analysis of both quantitative and qualitative data, which seems particularly relevant for the proposed work. A key feature of mixed methods research is its methodological pluralism or eclecticism, which frequently results in superior research (compared to mono-method research).

\section{FinAL THOUghtS}

Let me attempt to tie the proposed course and its teaching back to the Grand Challenges for Engineering as described by the National Academy. The Academy states in its Grand Challenge Scholars Declaration of Principles:

The profession of engineering has been, true to its Latin root ingeniare, about invention. For the past one hundred years, about as long as most college of engineering programs have existed, the list of the most important engineering achievements is dominated by devices: planes and spacecraft, cars and agricultural machines, lasers and PET scanners, to name a few from the National Academy of Engineering report of the last century. Almost a decade into the new century, another NAE committee has addressed the new engineering grand challenges and come to a much deeper unfolding of invention: Their list includes making solar energy economical, preventing nuclear terror, advancing health informatics, clean water and reverse engineering the human brain. None of them are just devices. Nearly all address complex social issues that require innovative technology and systems approach to solve but cannot be solved in a vacuum. They will also require engineers to shape public policy, transfer technical innovation to the market place, and to inform and be informed by social science and the humanities. These are challenges to "change the world," and many of them are inherently global. (NAE, 2012)

I began the present work with a call for an integration of the skill of listening and of stopping or at least slowing down in the teaching of engineering. I have offered one idea or path as to how such a skill might be included in a specific course-that being an undergraduate fluid mechanics course in a bioengineering curriculum. The approach will include frequent and constant integration of meditation and other described techniques as well as a conscious effort to make connections among the subject matter and, in this case, the fluid mechanics of living systems. A research question is offered as is a theoretical foundation and methodology. If successful, understanding is increased and can be documented; I shall integrate the contemplative pedagogy in all of my teaching. Maybe I can create a bit of anti-entropy. I encourage others among us to also consider the idea.

\section{REFERENCES}

Alexander, D. (2004). Nature's flyers: Birds, insects, and the biomechanics of flight. Baltimore, MD: Johns Hopkins University Press.

Berger, S. A., Goldsmith, W. \& Lewis, E. R. (1996). Introduction to bioengineering. New York, NY: Oxford University Press.

Cole, M. \& Engstrom, Y. (1993). A cultural-historical approach to distributed cognition. In G. Salomon (Ed.), Distributed cognitions: Psychological and educational considerations. New York, NY: Cambridge University Press.

Emerson, R. W. (2000). The essential writings of Ralph Waldo Emerson. New York, NY: Modern Library.

Fleischman, P. (1999). Karma and chaos: New and collected essays on vipassana meditation. Onalaska, WA: Parlyatta Research. 
Goethe, J. W. (1994). Goethe's collected works. Princeton, NJ: Princeton University Press.

Hart, T. (2004). Opening the contemplative mind in the classroom. Journal of Transformative Education, 2(1), $28-46$.

Johnson, R. B. \& Onwuegbuzie, A. (2004). Mixed methods research: A research paradigm whose time has come. Educational Researcher, 33(7), 14-26.

Kabatt-Zinn, J. (2005, February). Education as if it really mattered: The unification of knowing through contemplative practice. Paper presented at the Conference on contemplative practices and education: Making peace in ourselves and in the world. Teachers College, Columbia University, New York, NY.

Levey, J. \& Levey, M. (1998). Living in balance: A dynamic approach for creating harmony and wholeness in a chaotic world. Berkeley, CA: Conari Press.

National Academy of Engineering. (2008). Grand challenges for engineering. Washington, DC: National Academies Press. Retrieved from http://www.engineeringchallenges.org/?ID=11574

National Academy of Engineering. (2012). National Academy of Engineering Grand Challenge Scholars. Retrieved from http://www.grandchallengescholars.org/

Nelson, M. (2005, February). The Fruit of Silence. Paper presented at the Conference on contemplative practices and education: Making peace in ourselves and in the world. Teachers College, Columbia University, New York, NY.

Palmer, P. (1993). Keynote address. Keenan memorial lecture. presented at Berea College, Berea, KY.

Palmer, P. \& Zajonc, A. (2010). The heart of higher education: Transforming the academy through collegial convesations. San Francisco, CA: Jossey-Bass.

Peterson, R. O. (1995). The wolves of Isle Royale: A broken balance. Minocqua, WI: Willow Creek Press.

Postman, N. \& Weingartner, C. (1969). Teaching as a subversive activity. New York, NY: Delta.

Reynolds, 0. (1895). On the dynamical theory of incompressible viscous fluids and the determination of the criterion. Philosophical Transactions of the Royal Society of London. A, 186, 123-164.

Rilke, R. M. (2002). Letters to a young poet. New York, NY: Dover.

Rosenberg, L. (2004). Breath by breath: The liberating practice of insight meditation. Boston, MA: Shambhala Press.

Vogel, S. (1997). Life in moving fluids : The physical biology of flow. Princeton, NJ: Princeton University Press.

Vygotsky, L. S. (1978). Mind in society: The development of higher psychological processes. Cambridge, MA Harvard University Press.

Zajonc, A. (2005, February). Keynote address. Conference on contemplative practices and education: Making peace in ourselves and in the world. Teachers College, Columbia University, New York, NY.

Zajonc, A. (2006). Contemplative and transformative pedagogy. Kosmos Journal, 5(1), 1-3. 